\title{
ELEMENTOS PARA UN DIAGNÓSTICO DE LA VITIVINICULTURA EN MÉXICO
}

\author{
ELEMENTS FOR AN ECONOMIC DIAGNOSIS \\ OF VITIVINICULTURE IN MEXICO
}

\begin{tabular}{l|l} 
Wilfrido Ruiz Ochoa & $\begin{array}{l}\text { El Colegio de la Frontera Norte, } \\
\text { Campus Tijuana, México } \\
\text { wruiz@colef.mx }\end{array}$
\end{tabular}

\section{RESUMEN}

El sector vitivinícola nacional enfrenta como uno de sus principales problemas un rezago competitivo en términos de su grado de participación en los mercados nacionales e internacionales, así como una caída en sus niveles de producción. Lo anterior justifica la elaboración de un diagnóstico con enfoque internacional, lo cual aborda como objetivo el presente artículo.

Se parte de una metodología que valora los factores externos a las empresas que influyen en la formación de los precios relativos y de un ejercicio de elasticidades para estimar la demanda potencial ante una eventual eliminación de los impuestos especiales a la producción y servicios (IEPS).

Entre los resultados se destaca la existencia de un desaprovechamiento grave del potencial productivo, debido a: precios poco competitivos, restricciones estructurales que se presentan en los valles vitivinícolas para expandir la producción, condiciones desiguales en materia de comercio internacional y una carga fiscal internacionalmente excesiva.

Palabras clave: vitivinicultura, precios relativos, posicionamiento interno y externo, carga fiscal.

Clasificación JEL: O1, O18, Q1, Q17 


\begin{abstract}
The national wine sector confronts as one of its main problems, backwardness competitive in terms of their degree of participation in national and international markets as well as a declination in their level of production. This requires the elaboration of an international economic diagnostic, which is carried out as objective in the present article.

The methodology assesses the influence of external factors on the formation of relative prices, and implements of an elasticities model to estimate the potential demand, if excise taxes on production and services (IEPS) were eliminated.

As a result, is observed a serious waste of productive potential due to uncompetitive prices, structural constraints in wine valleys, unequal international trade conditions, and an excessive tax burden.
\end{abstract}

Keywords: viticulture, relative prices, internal and external positioning, and taxburden 


\section{INTRODUCCIÓN}

México es considerado el productor más antiguo de vino en Latinoamérica. $\mathrm{Su}$ industria vitivinícola aporta cerca de siete mil empleos directos e indirectos y genera una facturación de poco más de 40 millones de dólares ${ }^{1}$ (Aguilar, 2008). Sin embargo, la producción de vinos de calidad en el país es de un monto relativamente pequeño y enfrenta una fuerte competencia internacional en Estados Unidos, Latinoamérica y Europa. En particular por parte de Chile, Argentina, España, Francia e Italia. Además de que en los últimos años, Australia, Alemania y Portugal han emergido como nuevos jugadores.

Nuestro país no ha logrado posicionar del todo sus vinos en el mercado interno y, aunque nuestras exportaciones son cada vez más dinámicas, su monto todavía es sumamente modesto como para compensar el creciente flujo de vinos importados. Asimismo, en los últimos años la producción de vino en México ha tendido a caer, lo que compromete el potencial y desarrollo de sus valles vitivinícolas.

Este balance encuentra su explicación en factores de naturaleza estructural de fuerte componente territorial, en una competencia desigual por parte de países europeos y latinoamericanos, que disfrutan de subvenciones que no poseen los vinos mexicanos, y en factores institucionales, ambientales y económicos de origen interno que dificultan que el país aproveche su potencial vitivinícola y que compita internacionalmente.

Dado este contexto es necesario elaborar un diagnóstico económico con enfoque internacional, que vendría a complementar los pocos estudios

1 Estos datos se corroboraron con la Encuesta mensual de la industria manufacturera del Instituto Nacional de Estadística y Geografía, INEGI (2011), en la cual se reporta que hasta 2010 el valor de la industrialización de uva que deriva en la producción de vinos de mesa fue de 518.4 millones de pesos, esto es, poco más de 47 millones de dólares. Se excluyen de estos cálculos los vinos licorosos, la champaña, los jugos, pastas y otros derivados de la uva. 
de corte económico que se han elaborado sobre la vitivinicultura mexicana. Al respecto destacan las tesis de Villa (2002) y Sánchez (2007) y el trabajo de Sánchez y Mungaray (2010), que ponen el acento en los factores territoriales e institucionales que inciden sobre la competitividad y el desarrollo del sistema productivo local de los valles vitivinícolas, así como en la influencia que ejercen los procesos técnico productivos sobre la calidad del vino. Se han realizado también estudios que abordan los orígenes, las estrategias y el potencial de las empresas que conforman la vitivinicultura nacional, por ejemplo, Chávez (1996) y Armenta (2004).

El presente estudio tiene como objetivo explorar los factores externos a la empresa vitivinícola que inciden sobre su desarrollo y grado de competitividad, entre los que se encuentran: la liberalización comercial en el sector, la escasez de agua y otros recursos en los valles, la reducida escala productiva, costos de transacción extraordinarios, competencia internacional desigual, crecientes costos de comercialización y, sobre todo, analizar el impacto de un marco fiscal interno desproporcionado. Se explora cómo dichos factores han influido sobre una tendencia declinante de la producción que se observa en los últimos treinta años y en que el producto obtenido de los valles vitivinícolas sea relativamente caro. Todo ello compromete el desarrollo regional y turístico de las zonas donde tiene lugar esta actividad.

El artículo se divide en ocho secciones: 1) introducción, 2) enfoque teórico-metodológico; 3 ) comportamiento de la producción, de las ventas y el consumo interno; 4) balanza comercial y posicionamiento de las exportaciones de vino; 5) competitividad vía precios relativos; 6) factores que explican el diferencial en precios en el ramo, antes, durante y después de la producción (la cual se subdivide en dos sub secciones), 7) impactos sobre la demanda ante una hipotética eliminación de impuestos especiales y 8) conclusiones, aquí se resumen los principales hallazgos. 


\section{ENFOQUE TEÓRICO-METODOLÓGICO}

El diagnóstico que aquí se presenta sigue un enfoque internacional que no pretende ser exhaustivo, pero sí recupera algunos de los principales elementos de un análisis de este tipo: (1) la competitividad internacional en términos de costos y diferenciación del producto y (2) el potencial del ramo investigado para atender una mayor demanda vinícola nacional e internacional, ante un escenario de reducción de precios finales atribuible a menores impuestos.

Estos elementos del análisis son abordados parcialmente desde los enfoques teóricos de las ventajas competitivas y el comercio intraindustrial y desde el sustento metodológico que brinda la teoría microeconómica convencional. El planteamiento transversal consiste en que, actualmente, el intercambio internacional del vino ocurre en un contexto de competencia donde el diferencial en precios relativos se ha impuesto como uno de los principales factores que ha definido el grado de inserción y posicionamiento en los mercados internacionales $y$, en este sentido, de la competitividad. $^{2}$ Sin embargo, dado su menor nivel de producción y las condiciones territoriales de sus valles, nuestro país ha adoptado como enfoque competitivo la diferenciación del producto por calidad y variedad, lo cual le ha permitido atender sólo algunos nichos de mercado, requiriéndose valorar nuevamente esta estrategia.

Al respecto, Porter (1991) señala que las ventajas competitivas pueden alcanzarse mediante dos vías: un liderazgo que redunde en menores

2 Según Porter (1991), la competitividad se concibe como la medida en que las empresas logran incrementar su participación en los mercados a partir del desarrollo de ventajas comparativas propias del entorno regional y ventajas competitivas referentes a capacidades para concebir nuevas formas de realizar las actividades o funciones de la empresa y emplear nuevos procedimientos, tecnologías o insumos. 
costos relativos o la diferenciación del producto. Ambas estrategias pueden ser decantadas o fijadas sobre una de ellas, definiéndose entonces el enfoque competitivo. Pero cualquiera que sea este, la empresa no podrá descuidar los costos relativos frente a sus competidores.

Porter agrega que los costes van a estar definidos por la eficiencia con la que se llevan a cabo las funciones de la empresa, las cuales van conformando la cadena que agrega valor a cada fase del proceso de producción: antes, durante y después de la misma. En este artículo se analizan, principalmente, los factores externos que influyen sobre los costos de algunas de las fases.

El análisis comparativo internacional se centra entre países productores de vino, ya que se trata de un ramo donde se da de manera significativa el comercio intraindustrial debido a que el consumo de este tipo de producto tiende a ser afianzado por la misma capacidad productiva de vino. Desde esta perspectiva, y a diferencia del marco teórico de las ventajas comparativas, las exportaciones e importaciones simultáneas de bienes que se encuentran clasificados dentro de una misma categoría industrial son posibles, fuera del marco clásico de la dotación diferenciada de factores productivos. En su lugar, las motivaciones de dicho tipo de comercio se encuentran en la diferenciación por calidad, presentación y variedad, y no sólo en función de los costos relativos.

En los modelos que han intentado ofrecer una explicación de los flujos de comercio intraindustrial se ha partido de la premisa de que ningún país puede producir todas las variedades de un producto, porque no lograría aprovechar las economías de escala internas a la empresa (Dixit y Stiglitz, 1977). Hay también quienes han combinado tanto esta premisa como la de dotación relativa de factores (Helpman y Krugman, 1985) para explicar la coexistencia del comercio interindustrial e intraindustrial. 
Finalmente, destacan autores que diferencian el comercio intraindustrial en horizontal y vertical. En el primer caso, el intercambio ocurre entre productos similares; mientras que en el segundo se da entre productos idénticos, pero diferentes en cuanto a calidad (Falvey, 1981). Quizá esto último explique el intercambio de vinos entre países productores, por estar condicionado no solamente a la abundancia de factores sino también a las características singulares de los mismos.

El trabajo enmarca este tipo de intercambio comercial en la teoría del comercio intraindustrial, como justificante del estudio de las ventajas competitivas en la formación de precios entre países productores de vino. Se resaltan los factores externos que influyen en la constitución de los costos, entre los que se encuentran los impuestos indirectos al consumo. Sobre esto, y como complemento del diagnóstico, se desarrolla un ejercicio de elasticidades con el que se valora el potencial para atender una mayor demanda vinícola interna. El ejercicio se sustenta en el enfoque neoclásico para la medición de las elasticidad precio-demanda, mismo que puede encontrarse en cualquier libro de microeconomía intermedia (por ejemplo, Branson, 1985). Parte de la identidad básica del ingreso o facturación que, una vez descompuesta en tasas de cambio, puede derivarse de la misma la elasticidad-precio al asumir que no existen obstáculos estructurales para ampliar la oferta. El planteamiento matemático del ejercicio se detalla en la sección ocho.

Las fuentes de información utilizadas fueron fundamentalmente secundarias, procedentes principalmente de la Organización de las Naciones Unidas para la Alimentación y la Agricultura (FAO, por sus siglas en inglés). En menor medida procede de las siguientes instituciones: Organización Internacional de la Viña y el Vino (OIV); Comisión Europea (EC); Oficina de Impuestos y Comercio de Alcohol y Tabaco de Estados Unidos (ATTTB); 
Administración Federal de Impuestos de Estados Unidos (FTA) y de otras instancias similares para Argentina, Chile, España y México que se citan al pie de cuadros y gráficas. De manera auxiliar se realizaron entrevistas anónimas en formato abierto durante agosto de 2012 a cuatro empresarios vitivinícolas localizados en Ensenada, Baja California, con la finalidad de identificar la problemática económica del sector. ${ }^{3}$

El documento resalta las grandes tendencias y el comportamiento de los principales competidores internacionales para México, lo que es útil para efectos de la planificación estratégica del sector investigado tal y como se plantea en Ramos y Sánchez (2013).

\section{COMPORTAMIENTO DE LA PRODUCCIÓN, LAS VENTAS Y EL CONSUMO INTERNO}

Según la Asociación Nacional de Vitivinicultores (ANV), en 2008 Baja California concentraba $83 \%$ de la producción de vino, le seguía Querétaro con 8\%, Coahuila, 4\% y Zacatecas con tan sólo 3\% (Aguilar, 2008). En conjunto, se destinan cerca de 3 mil 500 hectáreas al cultivo de uva para producir vino, de las cuales 2 mil quinientas corresponden a los valles bajacalifornianos. Esta producción nacional se traduce -según la misma ANV-, en cerca de 14 millones de litros al año.

El posicionamiento productivo de nuestro país en materia vitícola es débil si se le compara con los países con los que compite, aporta solamente 0.38\% de la producción mundial de vino, ocupó en 2009 el lugar número 24. Muy por debajo de Francia, España, Estados Unidos, Argentina, Alemania,

3 Las entrevistas fueron dirigidas a los directores o gerentes de las bodegas vitivinícolas. Dos de ellas se aplicaron a directivos del Sistema Producto Vid de Baja California y las dos restantes a vitivinicultores que producen vino artesanal o de autor. 
y Chile, que se encuentran dentro de los diez principales países productores de vino en el mundo (WI, 2011b). Pese a ello, el potencial productivo del país es considerable. De acuerdo con el Sistema Producto Vid de Baja California (SPVB, 2012), únicamente 33.6\% de las ocho mil hectáreas susceptibles de ser explotadas se encuentran sembradas, pudiéndose entonces duplicar la capacidad productiva de la vid.

Visto en perspectiva, la producción del vino en México alcanzó su mayor nivel entre 1981 y 1986, años en que se obtenían cerca de 30 millones de litros anuales. En contraste, en la actualidad sólo se produce un quinto de lo que se producía en esos años. Un factor que pudo haber contribuido a ello fue la reconversión paulatina del cultivo de uva para producir vinos fortificados hacia el cultivo de uvas para vinos de mesa. ${ }^{4}$ Fenómeno que parece haber experimentado el país durante la segunda mitad de los ochenta.

Pero, además de este giro en la orientación del mercado, hay razones para inferir que la política comercial pudo haber influido también en el comportamiento de la producción de vinos, ya que su caída resultó particularmente fuerte durante los noventa. Periodo en que el país consolida las bases de una política de liberación comercial que involucró no tan sólo el Tratado de Libre Comercio de América del Norte (TLCAN), sino también tratados comerciales con Chile y la Unión Europea. Las tendencias más recientes también han sido a la baja: en 2010 se produjeron poco más de ocho millones de litros, esto es seis millones menos que en 2007 (ver gráfica 1).

4 Con las estadísticas de la FAO no es posible diferenciar la producción de los distintos tipos de vino. 


\section{Gráfica 1}

Evolución de la producción de vino mexicano, 1961-2010
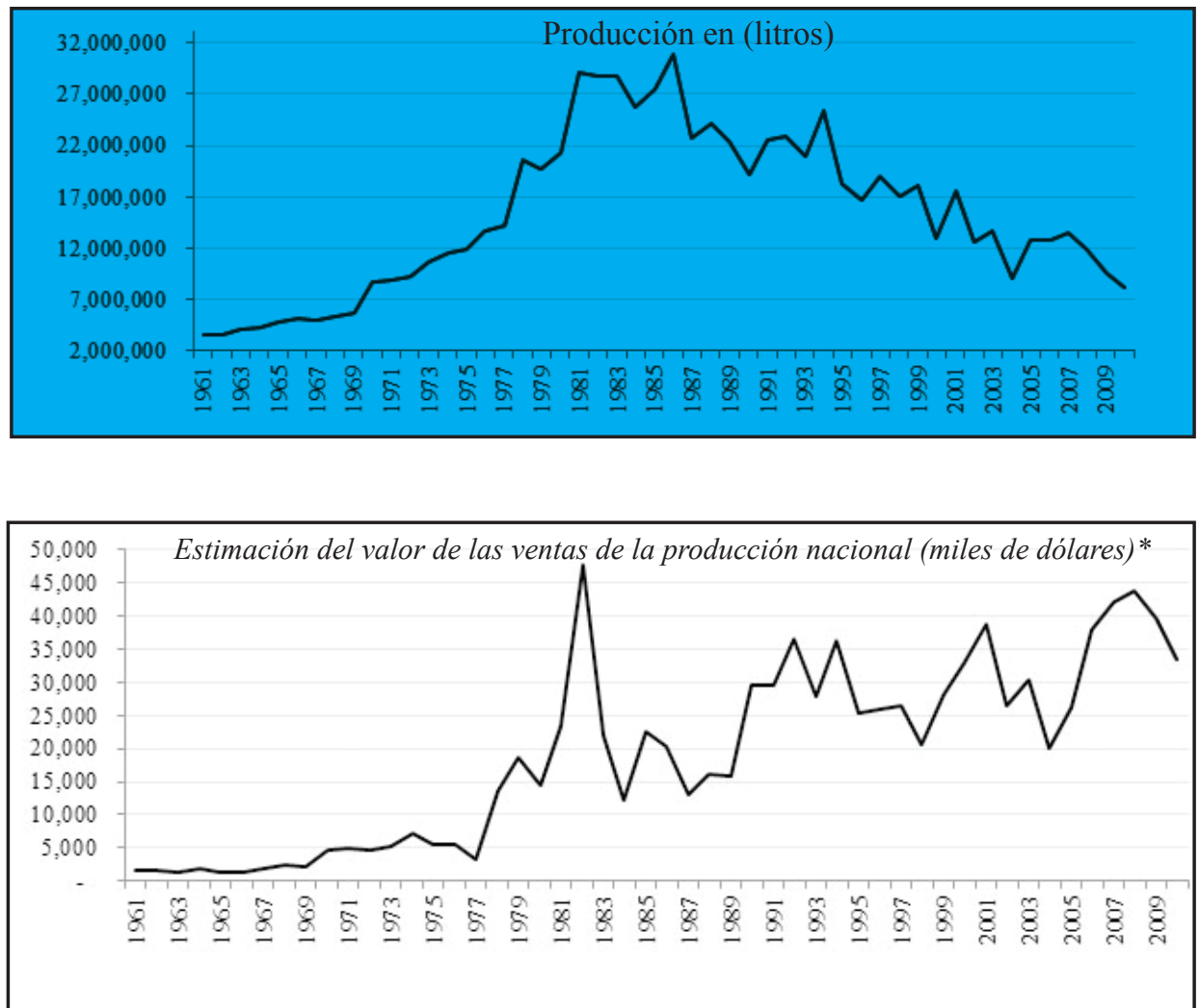

Fuente: con base en FAO (2013). (*) Las estimaciones del valor de las ventas se realizó con base en: el precio aparente de la producción exportada, la producción reportada por FAO y el valor de la facturación que declaró la Asociación de vitivinicultores en 2007 (Aguilar, 2008) y que se corrobora con datos del INEGI (2011).

Como puede observarse en la parte inferior de la gráfica 1, la tendencia de la producción vitivinícola de los últimos cinco decenios tiene la forma de una "u" invertida, la tendencia del valor de las ventas observa una tendencia ascendente debido al crecimiento de los precios, lo que refleja un cambio de estrategia que se orienta a producir vinos diferenciados internacionalmente, por su mayor calidad y variedad. 
En lo interno, a pesar de que el nivel de consumo de vino en México es de los más bajos del mundo (medio litro per cápita al año), ${ }^{5}$ al país no le es posible cubrir la demanda nacional con producción propia: se estima que $70 \%$ de nuestro consumo se cubre con vinos importados (SPVB, 2008). De manera que, tan sólo atendiendo la demanda del mercado interno, podría multiplicarse por tres la facturación del sector vitivinícola nacional. En este sentido, las potencialidades son muy significativas, sobre todo si consideramos que mientras que a nivel mundial el consumo per cápita de vino ha tendido a estabilizarse, en el caso de México ha tendido a crecer considerablemente. ${ }^{6}$

\section{BALANZA COMERCIAL Y POSICIONAMIENTO DE LAS EXPORTACIONES}

En los últimos años las importaciones de vino por parte de México se han elevado desproporcionadamente en comparación con su capacidad de exportación. Como consecuencia, el país arrastra un déficit creciente en su balanza comercial de vino que en 2005 ascendía a poco más de 100 millones de dólares y se elevó a 160 millones en 2010 (gráfica 2), cifra que contrasta con el superávit creciente de España, Francia, Argentina y Chile. Tan sólo en 2005 este último país alcanzó un superávit de 850 millones de dólares en su comercio internacional de vino.

5 En 2009 nuestro país ocupaba el lugar número 41 en el volumen consumido de vino, muy por debajo de Francia, Estados Unidos e Italia, que tenían el primero, segundo y tercer lugar, respectivamente, y de donde proviene el grueso de nuestras importaciones vinícolas. En América Latina, México se ubicó por debajo de Argentina, que ocupó el noveno lugar, y de Chile que alcanzó la posición 23 (WI, 2011a).

6 En 1997 se consumía, en promedio, 200 mililitros al año por habitante. Desde entonces el consumo medio en México ha observado una tendencia creciente: para 2004 se duplicó y en 2009 rebasó ligeramente el medio litro (OIV, 2013). 
Los pronósticos inerciales indican que, de no introducirse los cambios estructurales necesarios para incentivar el ramo, para 2020 México podría alcanzar un déficit de poco más de 200 millones de dólares. ${ }^{7}$ El rezago deficitario nacional ha tendido a crecer vertiginosamente, sobre todo a partir de la puesta en vigor en 1994 del TLCAN, y de la firma posterior de otros tratados comerciales con países latinoamericanos y europeos, entre los que se encuentran Chile (1999) y España y Francia (2000). De los tres países proviene $72 \%$ del vino extranjero. Si agregamos a Italia y Estados Unidos se tiene que casi $90 \%$ del vino importado por México procede de tan sólo cinco países (cuadro 1).

\section{Gráfica 2}

Balanza comercial del vino de México, 1961-2010

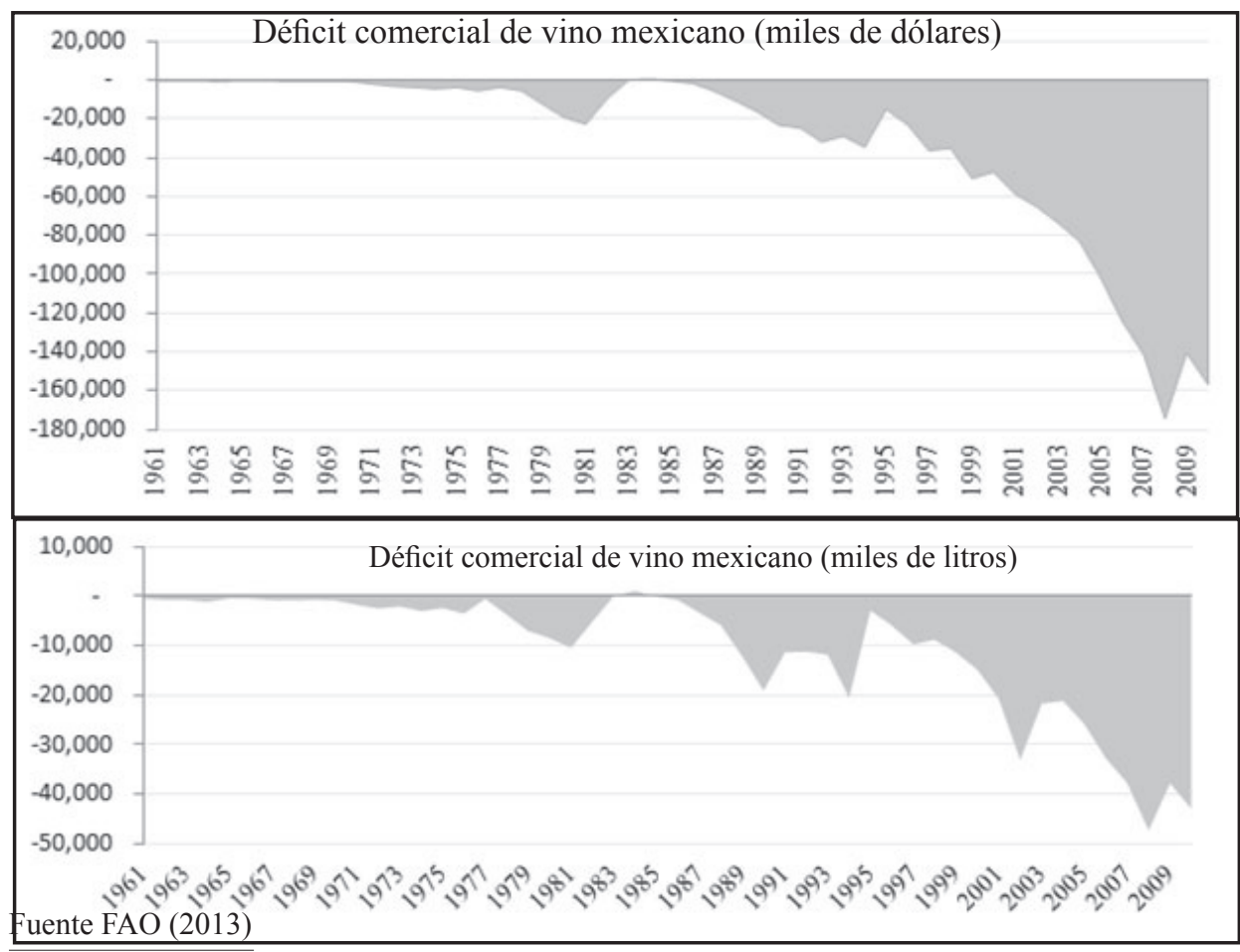

7 Se agradece el apoyo asistencial del Mtro. Cristian de la Luz Tovar quien elaboró los pronósticos a partir de un modelo no estacional de series temporales que se sustenta en las series originales de 1961-2005. 
Esta situación ha variado un poco en los últimos treinta años. España ha tendido a posicionarse cada vez más en el mercado nacional, Francia y Chile han tendido a perder terreno, mientras que Italia y Argentina se posicionan ya como competidores emergentes, de los que proviene casi $15 \%$ de las importaciones. Estados Unidos, por su parte, aunque su participación ha tendido a contraerse sigue siendo un competidor de gran relevancia ya que aporta poco más de $7 \%$ de las importaciones de vino mexicano, lo que representa, además, una fuerte competencia para el norte de nuestro país debido a su cercanía con el Napa Valley de California, entidad de la que proviene $89 \%$ de la producción vinícola norteamericana, $90 \%$ de las exportaciones de vino de Estados Unidos y en ella se ubican poco más de $40 \%$ de las bodegas vinícolas de ese país (WI, 2011b).

\section{Cuadro 1}

Principales países de donde provienen las importaciones de vino de México, 1990-2010

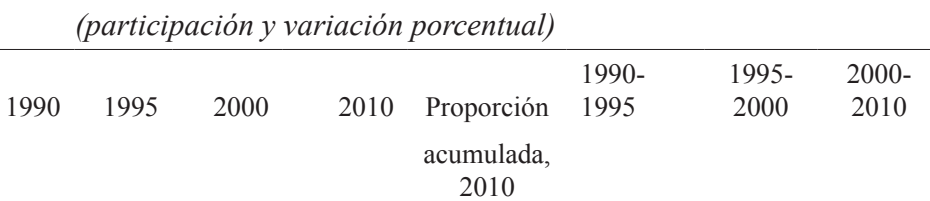

\begin{tabular}{rlrrrrrrrr}
\hline 1 & España & 22.63 & 21.86 & 26.93 & 30.42 & 30.42 & -0.76 & 5.06 & 3.49 \\
2 & Francia & 40.61 & 44.01 & 23.94 & 23.54 & 53.95 & 3.40 & -20.07 & -0.41 \\
3 & Chile & 1.96 & 8.61 & 24.21 & 18.16 & 72.11 & 6.65 & 15.59 & -6.05 \\
4 & Italia & 1.96 & 6.03 & 5.57 & 7.54 & 79.65 & 4.07 & -0.46 & 1.97 \\
& Estados & & & & & & & \\
5 & Unidos & 11.32 & 7.30 & 9.97 & 7.18 & 86.83 & -4.02 & 2.67 & -2.79 \\
6 & Argentina & 2.57 & 0.92 & 1.59 & 5.29 & 92.12 & -1.65 & 0.67 & 3.70 \\
7 & Alemania & 15.29 & 8.95 & 5.70 & 4.96 & 97.08 & -6.35 & -3.24 & -0.74 \\
8 & Portugal & 1.60 & 1.45 & 1.15 & 1.31 & 98.39 & -0.15 & -0.31 & 0.17 \\
9 & Australia & 0.00 & 0.01 & 0.12 & 0.78 & 99.17 & 0.01 & 0.11 & 0.66 \\
10 & Sudáfrica & 0.00 & 0.03 & 0.06 & 0.21 & 99.38 & 0.03 & 0.04 & 0.15 \\
\hline & Contribución & 97.94 & 99.18 & 99.25 & 99.38 & & & &
\end{tabular}

Fuente: elaboración propia con base en FAO (2013). 
Aunque el valor absoluto de las exportaciones mexicanas es todavía modesto (cerca de cinco millones de dólares), debe reconocerse su despunte, pese a que la estrategia productiva del país en materia vinícola sigue siendo predominantemente artesanal. Al respecto es destacable de las exportaciones: cobertura geográfica -el vino mexicano llega a cerca de 20 países-, calidad y aceptación mundial y cada vez mayor relevancia en relación con la capacidad productiva nacional (gráfica 3).

\section{Gráfica 3}

Evolución de las exportaciones de vino mexicano, 1961-2010

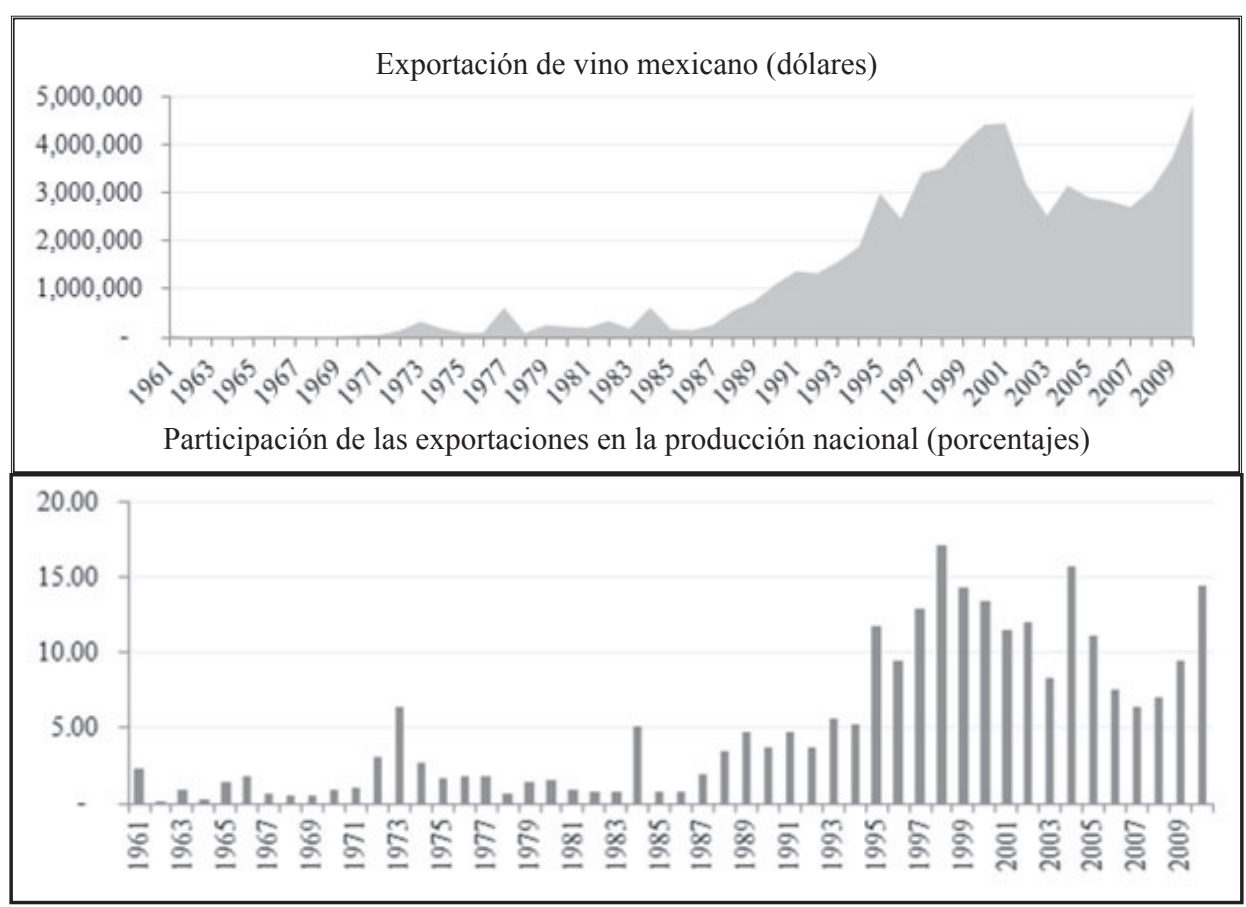

Fuente FAO (2013)

En el corto plazo el perfil de los países a los que se destinan las exportaciones tiende a variar con relativa rapidez, pero al considerar la participación promedio de los países compradores en las exportaciones 
mexicanas por quinquenio se observa que, históricamente, se ha destinado 30\% de nuestras exportaciones a Estados Unidos, le siguen Irlanda, Japón, Francia y Alemania. En conjunto, los cinco países dan cuenta de aproximadamente $68 \%$ del valor de las exportaciones (ver gráfica 4 ).

Con excepción de Francia y Estados Unidos, puede observarse que entre los países que presentan una alta capacidad productiva e impuestos especiales de cero a los vinos - como España, Portugal e Italia-, son a quienes nuestro país prácticamente no les vende vino. Se observa, además, que es mínima la capacidad para exportar vino a Latinoamérica: entre 1995 y 2010 las exportaciones a este continente apenas alcanzaron $2.45 \%$ del total. Como era de esperarse, prácticamente no se exporta nada a Chile y hacia Argentina apenas 0.2 por ciento.

\section{Gráfica 4}

Destino de las exportaciones mexicanas de vino, 1995-2010.

Participación promedio en los últimos cuatro quinquenios (porcentajes)

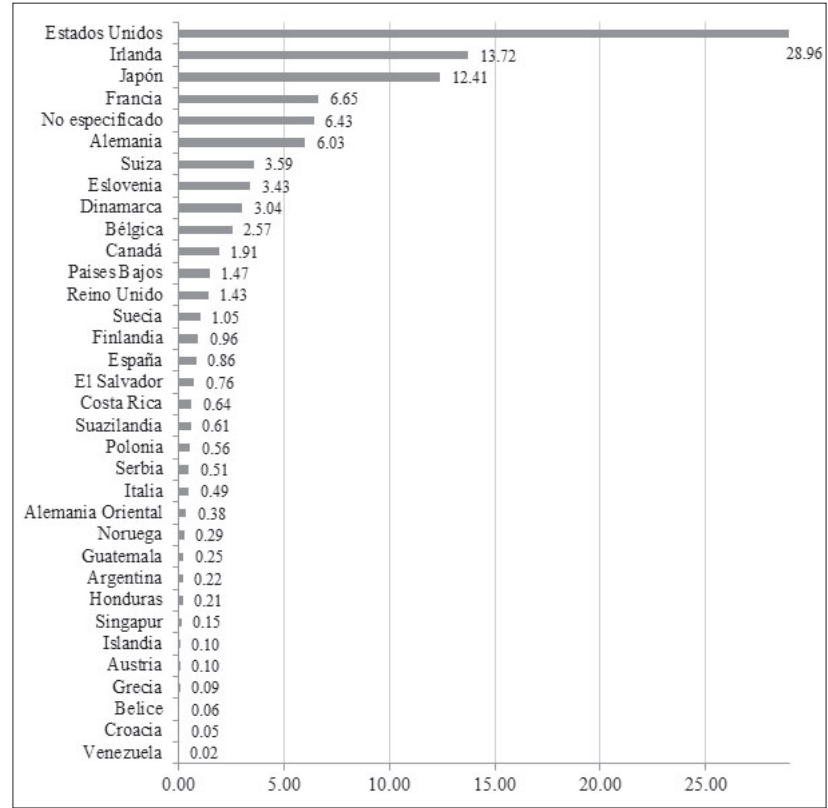

Fuente: elaboración propia con base en FAO (2013). 
De acuerdo con cifras de 2010 el intercambio internacional de vinos de tipo intraindustrial que parece ocurrir en forma más significativa es el que se da entre México y Estados Unidos. A este último se destina casi 29\% de las exportaciones vinícolas y, a la vez, proceden del mismo poco más de $7 \%$ de nuestras importaciones de vinos. De tal suerte que el primer mercado para los vinos de nuestro país representa a la vez, el quinto competidor más importante. Con Francia también se observa intercambio comercial de vinos con México en dos vías: a este país europeo se destinan 6.6\% de las exportaciones mexicanas y de Francia procede $7.18 \%$ de nuestras importaciones vinícolas. Algo parecido ocurre con Alemania: como destino de las exportaciones de nuestro país da cuenta $6 \%$ de las mismas y como competidor ha posicionado $5.3 \%$ de las importaciones vinícolas nacionales.

De manera que casi $42 \%$ de las exportaciones y poco más de $35 \%$ de las importaciones nacionales tienen lugar con tres países con los cuales se observa patrones de comercio intraindustrial en el ramo vinícola, lo que puede ser indicio de que nuestro país ha adoptado como enfoque competitivo predominante la diferenciación, y no tanto el liderazgo por costos. Dicha estrategia ha tenido un impacto ligeramente positivo sobre nuestra capacidad exportadora, si se mide ésta en proporción de nuestro nivel de producción, al pasar de 1\% durante los ochenta, a 15\% en 2010 (ver gráfica 3).

Sin embargo, en términos absolutos sigue siendo aún pequeño el valor facturado por ventas en los mercados internacionales, requiriéndose entonces complementar este análisis con el enfoque competitivo vía costos, para lo cual se revisan los precios relativos internacionales. 


\section{COMPETITIVIDAD VÍA PRECIOS RELATIVOS}

El vino mexicano es capaz de competir en términos de la calidad -así lo atestiguan los más de 300 premios internacionales que ha recibido-, pero no en términos de precios relativos, los cuales se ubican $50 \%$ por encima de la media global. Han tendido en las últimas tres décadas a posicionarse por encima del promedio de América del Sur, 50\% más altos. Desde 1997 esta tendencia se ha agudizado, superando los precios de los caldos mexicanos en poco más del doble a los de una botella de vino que se exporta desde Chile o Argentina (ver gráfica 5).

Como puede observarse en la gráfica 5 , históricamente los precios de los vinos mexicanos han tendido a ser más bajos que los europeos -sobre todo durante los setenta y la primera mitad de los ochenta-, pero desde 2005

\section{Gráfica 5}

Precios relativos de exportación del vino mexicano, respecto a los promedios del mundo, Europa, y América del Sur*

(A precios $F O B$, dólares corrientes por litro de vino)

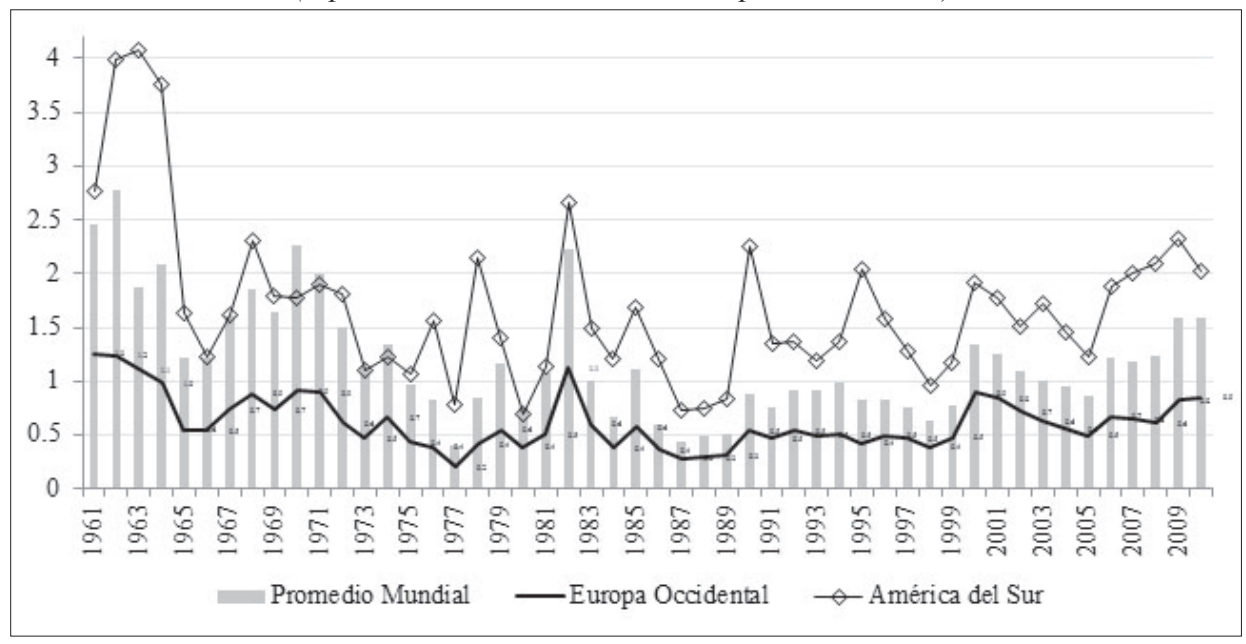

Fuente: FAO (2013). Nota: $(*)$ precios relativos definidos como el cociente entre el precio promedio aparente del litro de vino mexicano exportado y el precio similar para el país o región a comparar. 
han tendido a igualarse. Esto último podría estar influenciado por la reciente desaceleración económica que enfrentó Europa y que afectó a la alza los costos de producción, aun así, en media el vino mexicano en 2010 seguía siendo 20\% más económico que el europeo. ${ }^{8}$

En el caso de Chile -con quien México mantiene un acuerdo comercial desde 1998-, se observa que el diferencial en precios ha tendido a ensancharse. Cuando inició el tratado el nivel promedio del precio de los caldos chilenos era muy similar al de México, en la actualidad los vinos nacionales son $120 \%$ más caros. Además, las series de precios relativos México-Chile y México-Estados Unidos que se muestran en la gráfica 6 son sumamente parecidas, lo que podría indicar que Chile ha seguido una estrategia competitiva por costos muy agresiva para conquistar el mercado estadounidense y mexicano. Indexar prácticamente sus precios relativos con México, a los existentes entre nuestro país y Estados Unidos. No es así en el caso de Argentina, que ha seguido un comportamiento errático, pero ha mantenido siempre precios relativos menores a los de México y Estados Unidos hasta 2010, en relación con los de Chile (ver gráfica 6 y cuadro 2).

8 En 2010 el cociente entre el precio por litro del vino mexicano exportado y el de su similar europeo fue de 0.80 (ver gráfica 5). De ello derivó que en ese año el vino mexicano fuera $20 \%$ más económico. 


\section{Gráfica 6}

Precios relativos del vino mexicano para exportación, respecto a los de los principales competidores, 1961-2010 (*)

(Valuados a precios $F O B$, dólares corrientes por litro de vino)
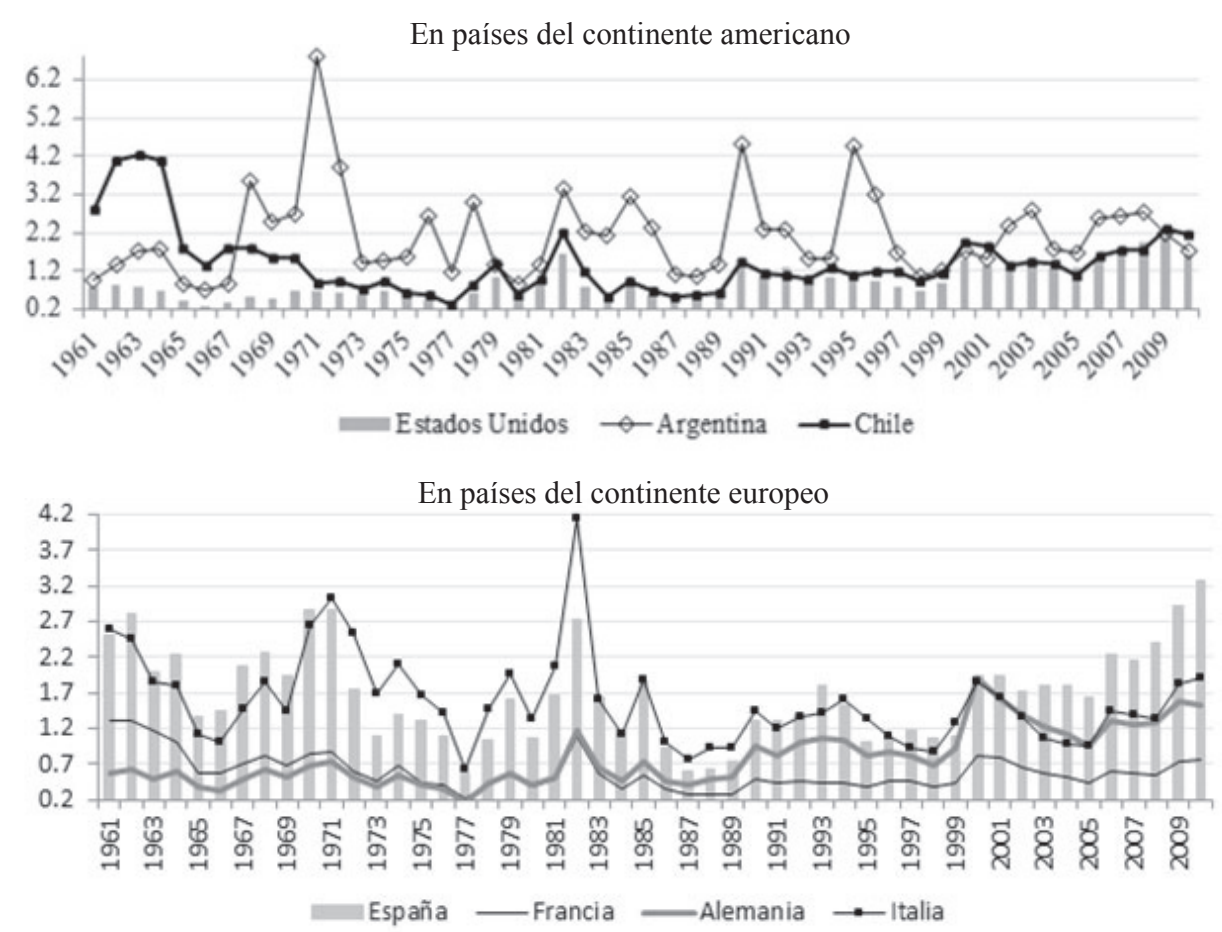

Fuente: FAO (2013). Nota: $\left(^{*}\right)$ precios relativos definidos como el cociente entre el precio promedio aparente del litro de vino mexicano exportado y el precio similar para el país o región a comparar. 


\section{Cuadro 2}

Precios aparentes de los vinos para exportación en países seleccionados, 1980-2010 (valuados a precios $F O B$, dólares por litro)

\begin{tabular}{|c|c|c|c|c|c|}
\hline & 1980 & 1990 & 2000 & 2010 & \\
\hline País/ Año & & & & & $2010 / 1980$ \\
\hline América Latina & 0.84 & 1.04 & 1.87 & 2.54 & 3.01 \\
\hline México & 0.75 & 1.70 & 2.80 & 4.53 & 6.08 \\
\hline Perú & 0.68 & 0.88 & 2.91 & 2.79 & 4.12 \\
\hline Argentina & 0.89 & 0.38 & 1.61 & 2.62 & 2.96 \\
\hline Chile & 1.30 & 1.20 & 1.43 & 2.11 & 1.63 \\
\hline Brasil & 0.61 & 1.04 & 0.56 & 0.63 & 1.03 \\
\hline Norteamérica & 1.03 & 1.78 & 2.44 & 2.31 & 2.24 \\
\hline Estados Unidos & 1.02 & 1.35 & 1.92 & 2.75 & 2.70 \\
\hline Canadá & nd & 2.22 & 2.97 & 1.86 & $0.80 *$ \\
\hline Europa & 1.31 & 2.09 & 2.07 & 3.17 & 2.59 \\
\hline Francia & 1.96 & 3.46 & 3.40 & 5.95 & 3.04 \\
\hline Portugal & 1.50 & 2.70 & 2.50 & 3.19 & 2.13 \\
\hline Alemania & 1.86 & 1.78 & 1.46 & 2.96 & 1.59 \\
\hline Italia & 0.56 & 1.19 & 1.52 & 2.36 & 4.22 \\
\hline España & 0.70 & 1.31 & 1.45 & 1.38 & 1.98 \\
\hline Otros países & 1.24 & 1.96 & 2.17 & 2.22 & 1.85 \\
\hline Australia & 1.53 & 2.51 & 2.91 & 2.45 & 1.60 \\
\hline Sudáfrica & 0.95 & 1.42 & 1.44 & 1.99 & 2.10 \\
\hline
\end{tabular}

Fuente: elaboración propia a partir de FAO (2013). Notas: $(*)$ Precios aparentes definidos como el cociente entre el valor de las exportaciones, entre la cantidad de unidades de 750 mililitros exportadas.

En el continente europeo hasta 2001 -año en que se firma el Tratado de Libre Comercio de la Unión Europea (TLCUE) con México-, tanto España como Italia seguían niveles de precios relativos muy similares respecto a nuestro país. A partir de ese año el vino español tendió a un aba- 
ratamiento en relación con los de México, a tal punto que ahora nuestros vinos son $220 \%$ más caros.

En este sentido, podría plantearse, como hipótesis que México perdió terreno al mantener un enfoque competitivo por diferenciación, mientras que España mejoró su penetración en el mercado mexicano desde el año 2000, al transitar a un enfoque competitivo por costos (ver cuadro 1). En cambio, aunque los precios relativos en relación con los caldos italianos también han tendido a reducirse, estos sólo son $80 \%$ más baratos que los de México y su penetración porcentual en el conjunto de las importaciones nacionales, también, es considerablemente más baja que la de los vinos de España (30\% contra 7.5 por ciento).

Únicamente Francia ha seguido una tendencia consistente a lo largo de las últimas cuatro décadas: se distingue por ofrecer vinos de calidad a precios relativamente altos, de esta forma sigue un patrón muy alejado del eje español-italiano. Desde la puesta en vigor del TLCUE, sin embargo, la brecha entre el precio promedio de los vinos franceses y mexicanos ha tendido a reducirse, pero aun así los nuestros continúan siendo 30\% más económicos, lo que podría ser indicio de que Francia, al mismo tiempo que explota ventajas competitivas por diferenciación para exportar a México, también ha desarrollado ventajas vía costos.

En definitiva, nuestro país debe revalorar el enfoque competitivo por diferenciación que parece dominar hasta ahora y revisar su posicionamiento en términos de costos. Debe tenerse en cuenta para esta aseveración que, desde 1980, el precio promedio del vino mexicano ha crecido cinco veces, ubicándose entre los más altos de Latinoamérica. Ningún otro competidor de este continente, de Europa o Norteamérica ha experimentado un crecimiento tan elevado, México queda fuera de la competencia vía precios frente a Estados Unidos, España, Italia, Alemania y también respecto 
a Sudáfrica, Portugal, Australia y Canadá, países que han surgido como competidores emergentes (ver cuadro 2). Se requiere, entonces, revisar los factores que inciden sobre la formación de los precios finales.

\section{FACTORES QUE EXPLICAN EL DIFERENCIAL EN PRECIOS ANTES, DURANTE Y DESPUÉS DE LA PRODUCCIÓN}

\subsection{Antes y durante la producción}

El crecimiento de los precios del vino mexicano ha permitido mantener su valor de producción a costa de un desaprovechamiento del potencial productivo de las zonas vitivinícolas del país y de la oportunidad que representa el mercado nacional e internacional. El diferencial en precios relativos con nuestros competidores es alto aun antes de impuestos, existen factores vinculados con las fases previas a la producción, y que ocurren durante la misma, que lo explicarían. Entre esos factores figuran algunos de carácter interno, como es la escasez de agua en los valles vitivinícolas de Baja California, ${ }^{9}$ lo que ha derivado en mayores costos, bajos volúmenes de producción, que se acentúan por la presencia mayoritaria de pequeñas y medianas empresas a las que se les dificulta el aprovechamiento de economías de escala ${ }^{10}$ y en una reducida diversificación del producto en cuanto a precio y calidad.

9 En 2003, 20\% de los pozos que proveen de agua al Valle de Guadalupe se encontraban sobre explotados, lo cual -de acuerdo con el Programa integral de agua de Ensenada (PIAE)- agudiza el problema de escasez de agua en Ensenada. De continuar esta tendencia, a partir del año 2017 la oferta total extraída será menor al consumo teórico esperado, se pronostica un déficit de 0.24 metros cúbicos por segundo para el año 2030 (IMIP, 2008: 103). 10 De acuerdo con Armenta (2004), a finales del decenio de los noventa el sector vitivinícola del país estaba constituido por 11 empresas, de las cuales dos concentraban $82.5 \%$ del mercado. Las restantes nueve eran pequeñas o medianas bodegas que no producían más de 30 mil cajas de vino al año. En 2008 -según el Sistema producto vid de Baja California- el número de productores que cultivaban tierras de 20 hectáreas o más era de 36 (SPVB, 2008). 
También se observan factores institucionales y organizacionales que dificultan el aprovechamiento de economías y oportunidades de mercado. $\mathrm{Al}$ respecto, la cooperación en red, así como los encadenamientos intersectoriales deben desarrollarse más, para lo cual a mediados de la década pasada se constituyó el clúster vitivinícola, siendo uno de los más emblemáticos en Baja California (Sedeco, 2004).

Como factores internos generalizables a otras actividades se encuentran: falta de crédito accesible para la micro y pequeñas empresas; rezago en materia de simplificación en la conducción de trámites para la apertura, seguimiento y crecimiento de los negocios y déficit en infraestructura y desarrollo social que caracteriza a los valles vitivinícolas, todo lo cual genera costos de transacción y financieros extraordinarios. ${ }^{11}$

Entre los factores externos que se presentan durante la producción, puede mencionarse como el más importante los diversos tipos de subvenciones y subsidios de algunos países europeos y latinoamericanos con los que se compite, lo que ha dado lugar a un comercio desigual y a la formación de organizaciones internacionales para combatirlas como barreras no arancelarias. ${ }^{12}$ En el caso europeo, el Instituto del vino de California plantea que las altas subvenciones que reciben los viticultores del viejo continente tan sólo para el cultivo de uva, limitan el ingreso de los vinos extranjeros a esa zona. ${ }^{13}$ Además, considera que la pretendida liberación

11 Algunos indicadores sobre el preocupante rezago que padecen los valles en cuanto a nivel de vida e infraestructura social, pueden consultarse en el Programa de desarrollo regional región del vino, verificándose que hacia el año 2000 , cerca de $40 \%$ de su población carecía de servicios de salud, $79 \%$ de la población de 15 a 24 años no asistía a la escuela, alrededor de $40 \%$ de las viviendas carecían de agua entubada y $45 \%$ de la población no ganaba más de dos salarios mínimos (Sedesol, 2006).

12 Por ejemplo, el World Wine Trade Grou.

13 A través de la Organización común del mercado (OCM) vitivinícola, la Unión Europea brinda ayuda a los vitivinicultores, no sólo en materia de producción sino también en relación con: promoción internacional; reestructuración de viñedos, protección contra 
de los derechos de cultivo que anuncia la revisión de la política agraria común (PAC) podría elevar todavía más los excedentes, lo que llevaría a una caída mayor de los precios de los vinos europeos con la consecuente intensificación de la competencia desigual con terceros países (WI, 2010). En Canadá algunas provincias que controlan la distribución de licor y vinos otorgan apoyos a productores nacionales (WI, 2010: 10), mientras que Estados Unidos proporciona trato fiscal preferencial a pequeños productores (USG, 2013: 26-USG-5041). En el contexto latinoamericano destaca Argentina por disponer de subvenciones públicas que justifica a través de planes estratégicos sectoriales ${ }^{14}$ y el reconocimiento otorgado al vino en 2010 como bebida nacional (INV, 2010).

Australia, Estados Unidos, Francia y Chile también disponen de planes estratégicos nacionales para apuntalar su sector vitivinícola. El primero de estos países cuenta, además, con planes regionales para periodos de cuatro o más años ${ }^{15}$ donde se inclina fuertemente por la investigación en el ramo, bajo fórmulas de participación mixta entre el Estado y el sector privado. ${ }^{16} \mathrm{En}$ contraste, en México se identifican pocos programas de apoyo a la vinicultura, pese a que SAGARPA y la Secretaría de Economía podrían incorporarla a sus programas modificándolos y adecuándolos (Font y Gudiño, 2009). Lo

fluctuaciones del mercado y seguro de cosechas en caso de desastre natural, entre otros aspectos (CE, 2008).

14 El plan estratégico Argentina vitivinícola 2020 disponía hasta el 2010 de 28 millones de dólares, de origen mayoritariamente gubernamental, para apoyar tanto la creación de centros de desarrollo vitícolas como a pequeños productores y a la promoción nacional e internacional (Coviar, 2011).

15 Como el Directions to 2025 ( WGGA, 2012, WT, 2013).

16 Han resultado sobre todo exitosas las funciones del Grape and Wine Research Development Corporation (GWRDC), la principal institución coordinadora de la investigación vitivinícola en Australia, cuyos fondos provienen, en parte, de recursos fiscales aportados por los empresarios y que re direcciona el Estado a la inversión para beneficio de los mismos. En 2004 de los 8.6 millones de euros invertidos en investigación vinícola, 4.1 millones los aportó el denominado Commonwealth (Castro, 2004). 
cierto es que la vinicultura no se encuentra incluida en los cultivos elegibles para programas de amplia cobertura, por el contrario, se le concibe como un ramo a contener por derivar en un producto que se considera nocivo para la salud.

\subsection{Durante la comercialización}

Durante la fase de comercialización intervienen otro tipo de factores, que elevan todavía más el diferencial en precios entre el vino extranjero y el nacional, como son: crecientes costos de comercialización nacional e internacional, una liberalización comercial que ha elevado los precios relativos del país frente a sus competidores extranjeros y un marco fiscal interno que ha resultado internacionalmente desproporcionado.

De acuerdo con entrevistas a directivos del sistema producto vid de Baja California, que se llevaron a cabo en agosto del 2012, la mayoría de las bodegas pequeñas y medianas no disponen de canales de distribución propios $\mathrm{y}$, salvo las grandes, no cuentan con puntos de venta o de representación en las principales ciudades, por lo que deben recurrir a comercializadoras cuyas comisiones suelen ser muy altas, que llegan a representar en ocasiones $30 \%$ del valor final de una botella de vino.

Los aranceles y otros derechos de importación también inciden en el precio final de los vinos. En esta materia México ha firmado diversos acuerdos comerciales con países productores, lo que ha permitido su importación libre de arancel. Desde julio de 2008, por ejemplo, se eliminó el arancel que hasta julio de 2007 se venía imponiendo a los vinos procedentes de la Unión Europea, con lo cual los caldos españoles, italianos, franceses y portugueses ingresan, prácticamente, sin pagar arancel alguno. En el caso de Chile sus vinos ingresan al nuestro en condiciones de libre mercado desde finales del año 2003. 
En Latinoamérica los integrantes del Mercosur imponen tan altos aranceles a terceros países, que llegan a elevar los precios de los caldos que importan hasta en 80 por ciento. ${ }^{17}$ Situación comparable, quizá, solamente con China y Corea del Sur, cuyos aranceles elevan en más de 50\% los precios de los vinos que importan (Llosas, 2011). Pese a este panorama, debe reconocerse que el ingreso de los vinos mexicanos al mercado norteamericano se ha facilitado gracias al TLCAN, de manera que desde 2011 se exporta vino a Canadá y Estados Unidos sin pago de aranceles.

Chile también es tratado de manera preferencial por Estados Unidos, a partir del primero de enero de 2015 sus vinos no pagarán arancel en ese país. Tampoco a su ingreso a la Unión Europea y, a diferencia de nuestro país, a partir de 2011 gozarán de ese tratamiento en Brasil y en 2015 en China (González, 2010). De esta forma, los caldos chilenos han resultado ser la principal competencia para los de México en los mercados donde mantenemos tratados comerciales.

Las tasas impositivas también inciden en la formación del precio final del vino, destacan en México los impuestos indirectos que son cubiertos por el consumidor aunque reportados por el empresario, con lo cual repercuten directamente en el precio final. Al respecto, los caldos mexicanos deben ser gravados tanto con el impuesto al valor agregado (IVA), como con el impuesto especial sobre productos y servicios (IEPS). Por su parte, los impuestos directos gravan fundamentalmente las ganancias y las inversiones, por lo que no serán analizados en esta ocasión.

En México, a diferencia de sus competidores, no se ha diferenciado el vino respecto a otras bebidas alcohólicas de mayor consumo, en relación con su impacto sobre la salud y los accidentes de tráfico. De manera que el

17 Es el caso de Brasil cuyo nivel arancelario es el más alto de Latinoamérica, a lo cual deben añadirse sus altos impuestos internos (SN, 2012). 
vino de mesa ha estado sujeto a cargas fiscales tan altas como la cerveza o el brandy, por lo que debe enfrentar un marco hacendario poco competitivo. Como muestra de ello en la gráfica 7 se estima la carga fiscal nominal de los vinos tranquilos o de mesa para los países que forman la Unión Europea, Estados Unidos, México, Chile y Argentina. Se observa que en el caso de los vinos mexicanos dicha carga fiscal nominal -que es la suma de las tasas o alícuotas de los impuestos indirectos al consumo- asciende a 41\%, lo cual resulta de la sumatoria de $16 \%$ de IVA y $25 \%$ de IEPS. Este umbral ubica a nuestro país en una posición poco competitiva respecto a la carga fiscal promedio que prevalece en la Unión Europea, que es de aproximadamente $25 \%$ y de la de Estados Unidos, que ronda alrededor de 13\% para una botella de seis dólares. ${ }^{18}$

Asimismo, es más elevada en comparación con los principales competidores: en Francia la carga fiscal es de 20\%, en Argentina, Italia y España de 21\%; en Alemania de tan sólo 19\% y en Portugal de 25 puntos porcentuales. De estos seis países -que presentan un diferencial impositivo nominal de al menos 20 puntos con México- procedió $71 \%$ de las importaciones durante el año 2010, lo que indica que las condiciones impositivas internas sí influyen sobre el posicionamiento productivo.

El diferencial en cuanto carga fiscal nominal respecto a Estados Unidos es todavía mayor, $13 \%$ para vinos de seis dólares y $19.5 \%$ en el caso de una botella de 12 dólares. Aunque este balance puede variar por entidad o

18 Mientras México, Argentina y Chile cuentan con un sistema federal de tasas porcentuales fijas (para IVA o impuestos especiales), Estados Unidos y Europa combinan tasas porcentuales para el caso de los impuestos a las ventas o del IVA y accisas expresadas en dólares o euros para los impuestos especiales al vino.Para compararlos fue necesario normalizar las accisas estadounidenses y europeas en función de tres precios hipotéticos antes de impuestos: de tres, seis y doce dólares, obteniéndose así tasas nominales para esos precios. En Estados Unidos se consideraron, además, los promedios interestatales de las cargas fiscales locales y estatales aplicables al vino. 


\section{Gráfica 7}

Carga fiscal nominal del vino de mesa en Estados Unidos, América Latina y Europa, para precios antes de impuestos de doce, seis y tres dólares por botella de 750 mililitros

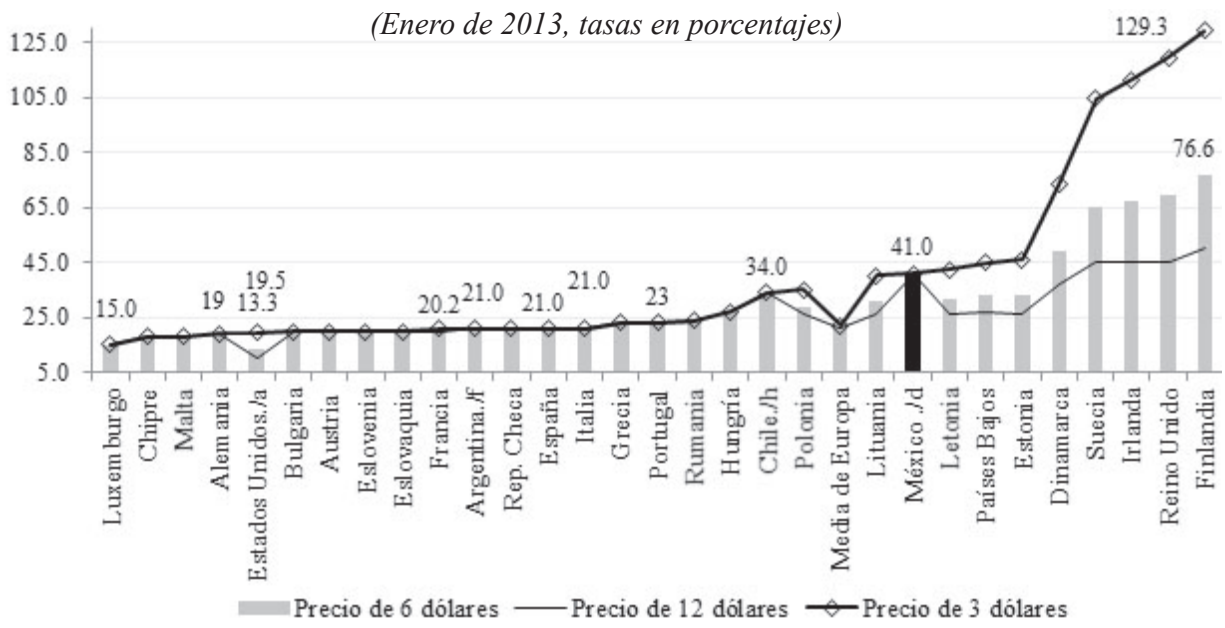

Fuente: Para Estados Unidos los promedios de los impuestos estatales específicos al vino proceden de FTA (2013), y TF (2011); los impuestos estatales a las ventas de TPC (2012 y 2013) y USSTS (2012) y los impuestos especiales federales al vino de ATTTB (2013). Para Europa, el IVA de EC (2013b) y las accisas especiales de EC (2013a). En los países latinoamericanos se consideró el IVA y los impuestos especiales al vino de la legislación SCA (1996 y 1997). De la misma forma, en el caso de Argentina se registró lo indicado en MHC (2012), en Chile en PEM (2009 y 2011). Notas: $a$ vinos de hasta 14 grados de alcohol, $d$ hasta 14 grados y $f$ menos de 10 grados.

localidad, en media, el país del que proviene 7\% de nuestras importaciones asigna cargas nominales más bajas que la mayor parte de los países europeos y latinoamericanos. Incluso en Chile -que cuenta con una carga fiscal de $34 \%$ y sí dispone de impuestos internos especiales para el vino-, ha logrado una nominal respecto al nuestro de siete puntos porcentuales. Cifra que se eleva en términos reales, debido a que en Chile no se contempla un efecto piramidal entre los impuestos indirectos al vino ${ }^{19}$ (MHC, 2012).

19 La carga fiscal real es el porcentaje que representa del precio después de impuestos, valor que habrá de añadirse al mismo para formar el precio final. Al considerar para tal fin que la base imponible incorpora, al menos, uno de los impuestos objeto de análisis, como ocurre en México. 
La carga fiscal nominal de los vinos mexicanos sólo es más baja en relación con los países nórdicos de Europa, el Reino Unido e Irlanda y, de acuerdo con el valor de la botella, con respecto a los Países Bajos, Letonia y Estonia. Este conjunto de países, sin embargo, no figuran como competidores del vino mexicano.

\section{IMPACTOS SOBRE LA DEMANDA ANTE UNA HIPOTÉTICA ELIMINACIÓN DEL IEPS}

Desde principios de 2011 se han realizado diversas propuestas para aligerar las cargas fiscales nacionales al vino. A principios de ese año, por ejemplo, la asociación mexicana de la industria vitivinícola propuso reducir en forma prolongada la tasa del IEPS, empezar por disminuir el gravamen de 25 a 10 por ciento, con el fin de fondear el desarrollo de seis zonas vitivinícolas, y crear un programa que contemplaría beneficios fiscales a cambio de inversión (Vega, 2011a, 2011b). Por su parte, desde la esfera política se ha propuesto la eliminación del IEPS para vinos de mesa, su reclasificación como bebida alcohólica fermentada no mayor a 16 grados de alcohol por volumen y liberar de trámites fiscales a empresarios que no produzcan más de cien mil litros de vino (SR, 2011, CD, 2012).

Tales propuestas no solamente abrirían oportunidades de desarrollo regional por los vínculos de la vitivinicultura con la agricultura y el turismo, sino también retos y riesgos. Para valorarlos se presentan los resultados principales de un ejercicio de elasticidades precio-demanda, que permite estimar la reacción de la demanda ante reducciones del precio final, que resultarían de una hipotética eliminación del IEPS sin considerar la respuesta de las importaciones. El ejercicio parte de la identidad básica del ingreso o facturación:

Julio - diciembre de 2014 - Págs. 9-50 
$Y=p^{*} q$

Dónde:

$\mathrm{Y}=$ valor de facturación de vino vendido por el productor (dólares)

$\mathrm{q}=$ producción de vino (litros)

$\mathrm{p}=$ precio aparente por litro vendido incluyendo IEPS e IVA (dólares)

A partir de (1) puede descomponerse la tasa de cambio del valor facturado como:

$\underbrace{\frac{\Delta Y}{Y}}=\underbrace{\frac{\Delta q}{q}}[\underbrace{\frac{\Delta p}{p} * \frac{q}{\Delta q}}]+[\underbrace{\frac{\Delta q}{q} * \frac{p}{\Delta p}}] \underbrace{\frac{\Delta p}{p}}$

$\hat{Y} \hat{q} \frac{1}{E p d}$ Epd

Luego, (2) puede reescribirse como:

$\hat{Y}=\hat{q} \frac{1}{E p d}+\hat{p} E p d$

Dónde:

$\hat{Y}=$ tasa de crecimiento anual, del valor facturado

$\Delta \mathrm{Y}=$ variación de la facturación entre años (por ejemplo, $\mathrm{Y}_{\mathrm{t}}-\mathrm{Y}_{\mathrm{t}-1}$ )

$\hat{q}=$ tasa de crecimiento anual, de la producción

$\Delta \mathrm{q}=$ variación de la cantidad vendida entre años

$\Delta \mathrm{p} \quad=$ variación de los precios entre años

Epd $=$ elasticidad precio de la demanda

$\hat{p} \quad=$ tasa de crecimiento del precio de venta

Una vez definido (3) nos preguntamos: ¿en cuánto variaría la facturación de vino si se redujeran los precios como consecuencia de una eliminación de 25\% del IEPS? Para ello definimos la tasa de crecimiento de los precios, una vez descontado el IEPS, como: 


$$
\stackrel{\circ}{\hat{P}}=\left(\stackrel{\circ}{P}_{t}-P_{t-1}\right) / P_{t-1}
$$

Dónde:

$\stackrel{\hat{p}}{=}$ tasa de crecimiento de los precios, sin IEPS

$\stackrel{\circ}{P}_{t}=$ precio en el año $t$, sin IEPS

$P_{t-1}=$ precio en el año anterior a $t$, con IEPS

Al sustituir $\hat{p}$ por $\stackrel{\circ}{\hat{p}}$ en (3) y dejar todo lo demás constante se tiene que:

$\hat{Y}=\hat{q} \frac{1}{E p d}+\hat{p} E p d$

Dónde:

$\hat{Y}=$ es la tasa de crecimiento anual del valor facturado, una vez descontado el IEPS. Luego, el nuevo valor de la producción para el año $t$ sería:

$$
\stackrel{\circ}{Y}_{t}=\stackrel{\circ}{Y}_{t} * Y_{t-1}
$$

Dónde:

$\dot{Y}_{t}=$ nuevo valor facturado como resultado de la exclusión del IEPS en el año $t$

$\hat{\hat{Y}}_{t}=$ tasa de crecimiento del nuevo valor facturado en $t$

$Y_{t-1}=$ valor facturado del vino antes de la modificación del IEPS en el año $t-1$

Para llevar a cabo este ejercicio los precios aparentes después de IEPS e IVA $(p)$ se estimaron como resultado del cociente entre el valor a precios FOB y las cantidades exportadas que se reportan en las estadísticas de la FAO (2013). A este valor se le agregó 25\% del IEPS y en forma piramidal 
(un impuesto sobre otro) 16\% del IVA. Se supuso que los precios promedio antes de impuestos para consumo interno y externo son aproximadamente similares a estos últimos. De esta manera -como resultado del producto entre precios y cantidades- fue posible calcular el valor de facturación final $(Y)$, se corroboró que para 2010 coincidiera en forma cercana con lo registrado por el INEGI (2011). Todos estos datos fueron referenciados a litros como unidad de medida y se conviertieron a dólares a precios de 2003, con lo cual fue posible obtener las tasas de crecimiento real de precios y cantidades que se requieren para el planteamiento de las elasticidades.

Los resultados del ejercicio se muestran en el cuadro 3. Como parte de las oportunidades se constata que de 1997 a 2010 la reacción de la demanda de vino ante caídas hipotéticas en el precio hubiera resultado más que proporcional a la caída de este último. Entre 1997 y 2005 dicha reacción o elasticidad hubiera sido entre 20 y $374 \%$ superior, para después estabilizarse en $76 \%$ en 2009 . Resulta entonces erróneo justificar nuevos impuestos al vino con el argumento de que la meta recaudatoria no se verá afectada debido al carácter inelástico de este producto.

El análisis indica, además, que se hubiera alcanzado una mayor dinámica en el ramo vitivinícola si este hubiera sido capaz de atender la demanda liberada y llegar a facturar por este hecho 13.6 millones de dólares adicionales en 2010, respecto a los 33 millones registrados en ese año. Es decir, $41 \%$ más. 


\section{Cuadro 3}

Impactos de la eventual eliminación del IEPS sobre el crecimiento y la facturación del sector vitivinicola, 1991-2010

\begin{tabular}{|c|c|c|c|c|c|c|c|c|}
\hline Impacto/año & 1991 & 1997 & 2000 & 2005 & 2007 & 2009 & 2010 & \\
\hline \multicolumn{9}{|l|}{ Impacto sobre el crecimiento } \\
\hline $\begin{array}{l}\text { Tasa de crecimiento del valor facturado observado } \\
\text { (porcentajes) }\end{array}$ & -0.06 & 2.26 & 17.37 & 31.07 & 11.08 & -9.22 & -16.15 & \\
\hline $\begin{array}{l}\text { Tasa de crecimiento del valor facturado estimado } \\
\text { (porcentajes) }\end{array}$ & 14.43 & 22.13 & 54.63 & 112.46 & 19.92 & 10.91 & -15.42 & \\
\hline \multicolumn{9}{|l|}{ Impacto sobre facturación } \\
\hline $\begin{array}{l}\text { Valor de la facturación observada } \\
\text { (millones de dólares) }\end{array}$ & 29.5 & 26.5 & 32.9 & 26.3 & 42.0 & * 39.7 & 33.5 & $* *$ \\
\hline $\begin{array}{l}\text { Valor de la facturación estimada } \\
\text { (millones de dólares) }\end{array}$ & 33.7 & 31.7 & 43.4 & 42.6 & 68.1 & * 55.8 & 47.2 & $* *$ \\
\hline Incremento de facturación (millones de dólares) & 4.3 & 5.1 & 10.5 & 16.3 & 26.1 & * 16.1 & 13.6 & $* *$ \\
\hline $\begin{array}{l}\text { Incremento de la facturación respecto } \\
\text { a la observada (porcentajes) }\end{array}$ & 14.49 & 19.43 & 31.75 & 62.10 & 62.10 & * 40.61 & 40.61 & $* *$ \\
\hline Elasticidad precio de la demanda & -1.00 & -1.20 & -0.68 & -4.74 & nd & -1.76 & nd & \\
\hline
\end{tabular}

Fuente: elaboración propia con base en estadísticas de la FAO (2013). Notas: * ** supone que la elasticidad precio de la demanda se mantiene en 2007 respecto a 2005 y en 2010 respecto a 2009, respectivamente.

Así, el eventual descontrol del consumo o la posibilidad de perder un monto significativo de recaudación parecieran ser los menores riesgos de una eventual reducción o eliminación del IEPS al vino, dado el bajísimo nivel de su consumo per cápita en México y al hecho de que la aportación por concepto de impuestos especiales de la vitivinicultura apenas si representa $0.90 \%$ de lo que recauda la federación por concepto de IEPS. ${ }^{20}$ En todo caso, los retos principales consistirían: en evitar que medidas de este tipo motiven a productores de bebidas alcohólicas de consumo masivo a solicitar tratos similares y, sobre todo, en que la evidente incapacidad de

20 En 2010 el sector vitivinícola nacional aportó cerca de 6 millones de dólares por concepto de IEPS, lo que representa $0.15 \%$ de lo recaudado por este concepto nacionalmente. Por su parte, los importadores contribuyeron con 28 millones de dólares, $0.75 \%$ del IEPS recaudado (CEFP, 2012). 
oferta de la vitivinicultura nacional para atender en el corto plazo la totalidad de la mayor demanda que se derivaría de una reducción del IEPS conduzca a que una proporción significativa de la misma sea atendida por vinos importados, agudizándose incluso el déficit comercial en el ramo.

Ante una flexibilización del marco impositivo se espera que los competidores reaccionen con la eficiencia necesaria para evitar que el empresariado nacional atienda por completo el mayor mercado pues, a diferencia de nuestro país, varias de las economías de las que procede el vino importado se caracterizan por contar con los mayores excedentes del mundo, frente a los cuales palidece la producción de México. En 2009, por ejemplo, la producción de vino del país apenas representaba $2 \%$ de la de España, Italia y Francia, no más de 4\% de la de Estados Unidos, cerca de 8.5\% de la de Argentina y diez puntos porcentuales en relación con la de Chile (WI, 2011b).

México se enfrenta, además, al problema de la escasez de agua, al rezago de infraestructura y a otras restricciones estructurales, por ello la integración de un mayor número de hectáreas al cultivo de la vid sería lenta, lo que daría tiempo para el posicionamiento de los vinos extranjeros en el mercado nacional.

En virtud de estos riesgos y restricciones estructurales que enfrenta el ramo vitivinícola, no es posible secundar la propuesta de eliminar en forma repentina el IEPS aplicable a los vinos. Resulta más viable establecer un programa estratégico de reactivación productiva orientada a reposicionar la vitivinicultura hacia un enfoque competitivo que combine costos y calidad y que involucre como parte de su andamiaje un marco impositivo más competitivo, cuya flexibilización estaría condicionada al cumplimiento de metas de desempeño productivo y de desarrollo de las regiones donde se asienta la vitivinicultura. 
Sin modificación del IVA la tasa nominal del IEPS tendría que acercarse, en una primera fase, a una tasa de $15 \%$ para que nuestro país se aproxime a las alícuotas fiscales de Chile y se ubique ligeramente por debajo de la carga fiscal nominal que prevalece entre los países de la Unión Europea. En una segunda fase, la tasa de $10 \%$-alcanzable en un plazo quizá mayor- sería deseable para lograr competitividad fiscal respecto a los países de Europa del Este, Portugal y Alemania y en forma cercana en relación con España e Italia.

Una segunda recomendación tiene que ver con la necesidad de establecer un límite en la reducción del IEPS que tenga en cuenta: la participación del vino nacional en el consumo interno, el equilibrio compensatorio entre la pérdida recaudatoria del IEPS y la mayor recaudación esperada de IVA e ISR, la presión sobre la sustentabilidad ambiental de los valles vitivinícolas debido a la expansión productiva y los límites deseables en cuanto al consumo de vino.

Como tercera recomendación se encuentra la posibilidad de introducir estímulos fiscales a la industria vitivinícola nacional como los que se practican en algunos de los países con los que competimos. Por ejemplo: comprometer inversión y metas de desempeño competitivo, a cambio de una reducción gradual del IEPS o acreditación de inversiones contra el mismo impuesto y aplicar tasas preferenciales para productores pequeños o para vinícolas que muestren una alta integración nacional intersectorial.

\section{CONCLUSIONES}

Ante la pérdida creciente de competitividad — vía precios - de la vitivinicultura, es necesario revalorar el enfoque competitivo por diferenciación 
que hasta ahora ha predominado sobre el de costos, como vía para alcanzar una mayor penetración en el mercado interno y en los externos. En este marco se requiere revisar las desiguales condiciones de competencia entre México y los países europeos y latinoamericanos debido a factores institucionales no del todo controlables, a lo que se agregan, por una parte, las restricciones estructurales de orden territorial que prevalecen en los valles de la vitivinicultura y, por otra, un esquema fiscal que ha inhibido el potencial productivo y el aprovechamiento de un mercado interno hasta ahora insuficientemente atendido.

En un contexto de intensa liberalización comercial, de alta diferenciación de bienes y precios, de creciente consumo interno y de cargas fiscales sumamente altas, la elasticidad precio de la demanda de vino se encuentra lejos de comportarse en forma inelástica. En este contexto las actuales cargas fiscales nominales al vino, no sólo no resultan competitivas internacionalmente, sino que, además, han propiciado una redistribución del mercado entre vinos nacionales y extranjeros a favor de estos últimos. Se plantea como una recomendación para impulsar la capacidad productiva y de exportación, la reducción gradual de las cargas fiscales condicionadas al logro de metas en cuanto a expansión productiva, sustentabilidad ambiental y desarrollo regional y la introducción de estímulos públicos como los que se practican en los países con los que competimos, siempre y cuando no se antepongan a los tratados internacionales acordados.

Habrá de tenerse presente que la estrategia fiscal representa sólo uno de los múltiples componentes que se requieren para impulsar la vitivinicultura en nuestro país. Se necesita, sobre todo, un proyecto estratégico integral, viable y operativo que contemple planes de acción territoriales para los valles vitivinícolas del país. 


\section{REFERENCIAS}

Aguilar, María Luisa. 2008. "Radiografía del vino mexicano", Semanario Día Siete, México, pp. 50-63.

Alcohol and Tobacco Tax and Trade Bureau (ATTTB). 2013."Quick Reference Guide to Wine Excise Tax", United States Department of the Treasury, www.ttb.gov/tax_audit/taxguide.shtml

Armenta Cejudo, Ramón A. 2004. "Estrategias de mercado en la industria vitivinícola del noroeste", Región y Sociedad, XVI(31).

Branson, William. 1985. Teoría y política macroeconómica, FCE, 4ta reimpresión, México.

Cámara de Diputados (CD). 2012. Iniciativa que reforma y adiciona diversas disposiciones de la Ley del IEPS, a cargo del diputado Jaime Chris López Alvarado y suscrita por integrantes del Grupo Parlamentario del PRI, Gaceta Parlamentaria, núm. 3605-II, México, D.F. 18 de septiembre. http://gaceta.diputados.gob.mx/Black/Gaceta/Anteriores/62/2012/sep/20120918-II/Iniciativa-1.html

Castro Crichton, Catalina. 2004. Coordinación y organización de la industria vitivinícola Australiana y Chilena, tesis de maestría en economía agraria, Pontificia Universidad Católica de Chile.

Centro de Estudios de las Finanzas Públicas (CEFP) .2012. Ingresos Tributarios No petroleros, 2007-2011, Nota Informativa, LXI Legislatura de la Cámara de Diputados, México, D.F., 25 de Junio. http://www. cefp.gob.mx/publicaciones/nota/2012/junio/notacefp0412012.pdf

Chávez Ruíz, Leobardo. 1996. Desarrollo potencial de la industria del vino en Baja California: L.A. Cetto un estudio de caso, tesis de maestría en desarrollo regional, el Colegio de la Frontera Norte.

Consejo de la Unión Europea (CE). 2008. Reglamento (CE) nº 479/2008 del Consejo de 29 de abril de 2008, Bruselas, http://europa.eu/legisla- 
tion_summaries/agriculture/agricultural_products_mark markets/ ag0001_es.htm

Corporación Vitivinícola Argentina (COVIAR). 2011. Plan Estratégico Argentina Vitivinícola 2020, Buenos Aires, Argentina, http://www. redinnovagro.in/pdfs/7\%20-COVIAR\%20MAYO\%202012.pdf

Dixit, Avinash y Joseph Stiglitz. 1977. "Monopolistic competition and optimum product diversity", The American Economic Review, 67(3): 297-308.

European Commision (EC). 2013a. Excise duty tables. Part I Alcoholic Bevarages, Directorate General of Taxation and Customs Union, Brussels, http://ec.europa.eu/taxation_customs/resources/documen ts/taxation/excise_duties/alcoholic_beverages/rates/excise_dutiespart_i_alcohol_en.pdf

. 2013b. VAT Rates Applied in the Members States of the European Community, Taxation and Customs Union, Brussels, http:// ec.europa.eu/taxation_customs/resources/documents/ taxation/vat / how_vat_works/rates/vat_rates_en.pdf.

Falvey, Rodney. 1981. "Commercial policy and intra-industry trade", Journal of International Economics, 11(4): 495-511.

Federation of Tax Administrators (FTA). 2013. State Tax Rate on Wine, Washington, D.C., USA, January, http://www.taxadmin.org/fta/rate/ wine.pdf

Food and Agriculture Organization of the United Nations (FAO). 2013. FAOSTAT, The Statistics Division of the FAO, OUN, New York, USA, http://faostat.fao.org/default.aspx?lang=en

Font Playán, Isabel y P. Gudiño Pérez. 2009. "La industria vinícola mexicana y las políticas agroindustriales: panorama general", Redpol, núm. 2, julio-diciembre. 
Helpman, Elhanan y Paul Krugman. 1985. Market structure and foreign trade.Imperfect competition and the international economy, MIT Press, Cambridge, Massachusetts.

Porter, Michael. 1991. La ventaja competitiva de las naciones, Javier Vergara Editor, Argentina.

Ramos, Benito y Consuelo Sánchez. 2013. La planificación estratégica como método de gestión pública, INAP, España.

González, María Soledad. 2010. “Aranceles, una gran barrera para seguir creciendo", Área del Vino, 23 de septiembre, http://www.areadelvino.com/articulo.php?num=21334

Instituto Municipal de Investigación y Planeación de Ensenada (IMIP). 2008. Programa integral de agua de Ensenada (PIAE), Ensenada, Gobierno del Estado, CESPE y CODEEN.

Instituto Nacional de Estadística y Geografía (INEGI). 2011. Encuesta mensual de la industria manufacturera. Tabulado especial de la industrialización de uva, México, http://www.uva.gob. mx/index. php? portal=uva

Instituto Nacional de Vitivinicultura (INV). 2010. El vino fue declarado bebida nacional, Centro de Prensa, Argentina, noviembre, http:// www.inv.gov.ar/noticias.php?ind=1\&id_nota $=198$

International Organisation of Vine and Wine (OIV). 2013. Stat OIV Extracts, Francia, www.oiv.int/oiv

Llosas Via, Merce. 2011. "Los aranceles e impuestos que gravan la comercialización de productos en el exterior elevan el precio del vino hasta en un $70 \%$ en países como Corea del Sur o el 56\% en China", Granel Wine, 16 de junio, http://www.granelwine.com/?p=269

Ministerio de Hacienda de Chile (MHC). 2012. Decreto Ley No. 825, Ley Sobre Impuesto a las Ventas y Servicios, Servicio de Impuestos Inter- 
nos (SII) de Chile, Santiago de Chile, www.sii.cl/pagina/ jurisprudencia/legislacion/basica/d1825.doc, consultado el 27 de enero del 2013 Tax Foundation (TF). 2011. Wine Excise Tax Rate, September, TF, USA. http://taxfoundation.org/data

Tax Policy Center (TPC). 2012. Sales Tax Rates, State and Local 2004-2012,

Urban Institute and Brookings Institution, US, http://www.taxpolicycenter.org/taxfacts/displayafact.cfm?Docid $=492$

Tax Policy Center (TPC).2013. Sales Tax Rates 2000-2012, Urban Institute and Brookings Institution,EstadosUnidos.En: http://www.taxpolicycenter.org/ taxfacts/displayafact.cfm?Docid $=492$

Poder Ejecutivo de los Estados Unidos Mexicanos (PEM). 2009. Ley del impuesto al valor agregado, Diario Oficial de la Federación (DOF), 29 de diciembre, México, D.F., http://www.diputados. gob.mx/LeyesBiblio/pdf/77.pdf.

2011. Ley del impuesto especial sobre producción y servicios", Diario Oficial de la Federación (DOF), 30 de diciembre, México, D.F., http://www.diputados.gob.mx/LeyesBiblio/pdf/78.pdf.

Sánchez Zepeda, Leandro. 2007. Aproximación a la incidencia de la industria vinícola en el desarrollo económico del Valle de Guadalupe (México) y la Manchuela (España), tesis doctoral, Madrid, España. y Alejandro MungarayLagarde. 2010. "Vino de calidad: base de desarrollo endógeno en el Valle de Guadalupe", Frontera Norte, 22(44): 109-132.

Secretaría de Desarrollo Económico (Sedeco). 2004. Plan estratégico del clúster vitivinícola de Baja California, SEDECO, Tijuana, Baja California, Marzo.

Secretaría de Desarrollo Social (Sedesol). 2006. Programa de desarrollo regional región del vino, Comité de Planeación para el Desarrollo Municipal (Copladem), Ensenada, Baja California. 
Senado de la República (SR). 2011. Iniciativa con proyecto de decreto por la que se reforman y adicionan diversas disposiciones de Ley del IEPS, en materia de vinos de mesa mexicanos, LXI Legislatura, 13 de octubre, http://www.impactolegislativo.org.mx/monitor/documentos/iniciativas/14009.pdf

Senado y Cámara de Diputados de la Nación Argentina (SCA). 1996. Ley 24.674. Modificaciones a la Ley de Impuestos Internos de 1979, Boletín Oficial (B.O.), Agosto, actualizada al 10 de Abril de 2000, Buenos Aires Argentina, http://www.dae.com.ar/leg/leyes/124674.html.

. 1997. Ley del impuesto al valor agregado de la Ley No. 23.349, por decreto 280/97 y sus modificaciones al 2002, Boletín Oficial (B.O.), http://www.dae.com.ar/leg/leyes/iva/ivaleyin.html, consultado el 30 de enero del 2013.

Sistema Producto Vid de Baja California (SPVB). 2008. Proyecto integral para la competitividad del Sistema Producto Vid de Baja California, Ensenada, Baja California, octubre, http://afintegral. com/docs/SistemaProductoVid4Competitividad.pdf

2012. Información general del cluster vitivinícola, SPVB, Ensenada, Baja California, http://vidyvino.org/docs/SPVid_Info_Cluster.pdf Spanish News (SN). 2012. Brasil desestima aumentar impuestos y aranceles contra el vino extranjero, SN, 22 de octubre, http://spanish.news. cn/iberoamerica/2012-10/23/c_131923831.htm

United States Government (USG). 2013. United States Code (USC), Gallonage Taxes, Subpart C Wines, U.S. Government Printing Office, USA, http://www.law.cornell.edu/uscode/text/26/subtitle-E/ chapter-51/subchapter-A/part-I/subpart-C

United States House Representatives (UHR) .2011.Code of Federal Regulations (CFR). Title 27: Alcohol, Tobacco and Firearms, Part 24, 
Wine, Gobernment Printing Office, United States. En: http://www. ttb.gov/wine/wine_regs.shtml.

United States Sales Tax Site (USSTS). 2012. Table of US State Sales Tax Rates of January 2012, US Tax Network, http://www.usa-sales-usetax-e-commerce.com/table_sales_rates.asp.

Vega, Marielena. 2011a. "Vinos dice, ¿Adiós al IEPS?”, Inforural, México, 3 de febrero, http://www.info rural.com.mx/mercados.php?\&id_ rubrique $=4048$ id_article $=69898 \#$

.2011b. "Vino por IEPS y programa integral. El gremio avanza con la convicción de que la innovación será la herramienta más poderosa para competir con el vino de importación”, Excélsior, noviembre, http://www.excelsior.com.mx/2011/11/09/marielena-vega/781888

Villa Sánchez, Sughei. (2002). La competitividad en el sistema productivo local del vino en el Valle de Guadalupe, tesis de maestría en desarrollo regional, el Colegio de la Frontera Norte.

Wine Grape Growers Australia (WGGA). 2012. Strategic Plan 2013-2017, http://www.wgga. com.au/wp-content

Wine Institute (WI). 2010. International Trade Barriers Report for U.S. Wines, California, http://www. calwinexport.com. . 2011a. Per Capita Wine Consumption by Country-Ranked by Per Capita Consumption, California, http://www.wineinstitute.org/ 2011b. World Wine Production by Country, California, http:// www.wine institute.org/files/2010_World_Wine_Production_by_ Country.pdf

Wine Tasmania (WT). 2013. Strategic Plan 2011-2013, http://www.winetasmania.com.au/files/Strategic_Plan_2010-13_FINAL.pdf

World Wine Trade Group (WWTG). 2013. Official Website, http://www. wwtg-gmcv.org/ 